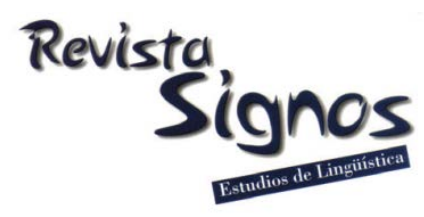

\title{
Teaching English oral presentations as a situated task in an EFL classroom: A quasi- experimental study of the effect of video- assisted self-reflection
}

\author{
Enseñanza de presentaciones en inglés como tarea situada en el \\ aula de inglés como lengua extranjera: Un estudio cuasi- \\ experimental de los efectos de la autorreflexión asistida por video
}

\author{
Xiangdong Li \\ XI'AN INTERNATIONAL STUDIES UNIVERSITY \\ CHINA \\ xiangdong813@gmail.com
}

Recibido: 12-VII-2016 / Aceptado: 11-IX-2017

\begin{abstract}
Video-assisted self-reflection (VASR) has been identified as an effective pedagogical tool in teacher education, and yet it has been rarely researched in the context of teaching EFL students to make oral presentations (OPs). This study aimed at investigating the effectiveness of VASR in teaching EFL students to make OPs and the students' perceptions of its pedagogical use. A quasi-experimental two-group pre-test post-test comparison design was used. The experimental group $(\mathrm{n}=14)$ and the control group $(n=15)$ experienced the same instructional procedures for 14 weeks, while only the experimental group made VASRs. Two questionnaires were used as instruments, one completed by both groups first as the pre-test and then as post-test to investigate the effectiveness of VASR, and the other completed by the experimental group to examine students' perceptions. The results suggested that VASR was effective in developing students' use of non-verbal elements in communication and that students perceived VASRs as beneficial activities. A structured protocol was recommended to facilitate students' VASRs and maximize its pedagogical effect. The findings have implications for the design of VASRs in teaching EFL students to make OPs.
\end{abstract}

Key Words: English oral presentation, video recording, video-assisted self-reflection, quasi-experimental study. 


\section{Resumen}

Se ha identificado a la autorreflexión asistida por video como una herramienta efectiva en la formación de profesores, pero casi nunca ha sido investigada en el contexto de enseñar a esos estudiantes de inglés como lengua extranjera al hacer presentaciones orales. Esta investigación pretende investigar la eficacia de la autorreflexión asistida por video como método de enseñar a estudiantes de inglés como lengua extranjera a hacer presentaciones orales, y las percepciones de estudiantes acerca del uso pedagógico de videos. Hemos empleado un diseño cuasi-experimental de pre-test/post-test, con dos grupos. El grupo experimental $(\mathrm{n}=14)$ y el grupo de control $(\mathrm{n}=15)$ recibieron la misma enseñanza durante 14 semanas, pero solo el grupo experimental hizo autorreflexión asistida por video. Se usan dos cuestionarios como instrumentos, uno rellenado por ambos grupos en la pre-test y de nuevo en la post-test para investigar la eficacia de autorreflexión asistida por video, y el otro completado por el grupo experimental solamente, para examinar las percepciones de esos estudiantes. Los resultados sugirieron que la autorreflexión asistida por video resultó efectiva para desarrollar el uso de elementos no verbales en la comunicación, y que los estudiantes pensaron que la autorreflexión asistida por video fue una actividad beneficiosa para ellos. Se sugirió un protocolo estructurado que puede facilitar la autorreflexión y aumentar sus efectos. Los hallazgos son importantes a la hora de diseñar la autorreflexión asistida por video para enseñar estudiantes de inglés como lengua extranjera cuando se hacen presentaciones orales.

Palabras Clave: Presentaciones orales en inglés, grabación de video, autorreflexión asistida por video, estudio cuasi-experimental.

\section{INTRODUCTION}

Creating and delivering English oral presentations (OPs) is a key employability skill and an important professional skill in students' future workplaces (Campbell, Mothersbaugh, Brammer \& Taylor, 2001; Adams, 2004; Jeon, 2005). As a result, development of students' oral communicative competence in English is one goal of the English curriculum in higher education, and OP is considered as one of the most useful tools to improve students' ability to communicate (Adams, 2004; 'Tsai, 2010; De Grez, Valcke \& Roozen, 2014). Refinement of presentation skills is thought to be eventually helpful for students in their future academic life and careers (ZappaHollman, 2007).

However, students may encounter difficulties when they prepare for and deliver their OPs. For example, research indicates that making English OPs is linguistically challenging for learners who are non-native speakers of English (Morita, 2000; Kobayashi, 2003; Jeon, 2005; Zappa-Hollman, 2007; Yang, 2010). Research also suggests that OP is psychologically challenging for learners, causing anxiety, nervousness, and lack of confidence (Morita, 2000; Jeon, 2005; Woodrow, 2006; Zappa-Hollman, 2007; Chen, 2009; Mahmud, 2013). This is particularly the case for silent and passive students in Asia, such as those from China, Japan, and Korea (Watkins \& Biggs, 2001; Woodrow, 2006; Bankowski, 2010). 
To effectively teach English OP skills, assisting students to perform self-reflection (SR) on their own OP performance is an important step (see Schön, 1983; Kolb, 1984; Smith, 2011), besides scaffolding students in creating and delivering OPs. The use of video recordings, a commonly used pedagogical tool in teacher education, has been identified as an effective form of SR in improving student teachers' performances (Dawson, Dawson \& Forness, 2001; Shepherd \& Hannafin, 2008; Tripp \& Rich, 2012a; McFadden, Ellis, Anwar \& Roehrig, 2014). Since both teaching and OPs are public oral performances, video recordings of students' own English OPs could be used as a pedagogical tool to assist students in making SRs.

The pedagogical use of OPs has been a popular topic in language teaching research (see Morita, 2000; Hill \& Storey, 2003; Kobayashi, 2003; Cheng \& Warren, 2005; Jeon, 2005; Tuan \& Neomy, 2007; Zappa-Hollman, 2007; Chen, 2009; Bankowski, 2010; Sundrarajun \& Kiely, 2010; Tsai, 2010; Yang, 2010; Chou, 2011; Mahmud, 2013; Kibler, Salerno \& Palacios, 2014). However, the effect of incorporating video-assisted self-reflection (VASR) in teaching OPs in an EFL (English as a Foreign Language) context has not been explored.

Against such a background, this study is intended to address two questions:

1. How effective is VASR in teaching EFL students to make OPs?

2. How do students perceive the pedagogical use of VASRs?

Using a quasi-experimental two-group pre-test post-test comparison design, the current study will add knowledge to the literature regarding the effective use of VASRs in teaching EFL students how to make OPs and inspire colleagues to explore VASR as a pedagogical tool in their own teaching contexts.

\section{Theoretical framework}

\subsection{Oral presentation}

In an EFL context, an OP refers to a form of public speaking where students, individually or in groups, present a prepared talk on a certain topic in English to the class with the help of visual aids (Chen, 2009; Sundrarajun \& Kiely, 2010). It occurs in a specific physical, social, and cultural context, with a certain theme and purpose of communication. The message is delivered from the speaker to the audience through linguistic, paralinguistic (intonation, volume, etc.), and extra-linguistic (gestures and facial expressions, etc.) elements. The intended meaning and its interpretation rely on the interaction between the production context and participants. It demands a combination of qualities: good knowledge of the topic of presentation, audiencefriendly organization of content, high levels of language proficiency, adequate online language-processing skills, ability to talk extemporaneously, effective delivery skills, appropriate display of paralinguistic elements (for example, body language, eye 
contact, etc.), engaging the audience, an element of performance (appropriate voice manipulation and bodily action), good psychological qualities (overcoming shyness, nervousness, and sense of insecurity and inferiority), sensitivity to the context (audience's response, etc.), register and discourse skills, a lucid presentation, adherence to specific behaviors valued by each discipline, and multimedia management (Morita, 2000; Tuan \& Neomy, 2007; Zappa-Hollman, 2007; Sundrarajun \& Kiely, 2010; Tsai, 2010; Chou, 2011).

Given the demanding and comprehensive nature of the OP task, it constitutes a powerful situated learning experience that leads to deeper understanding and better learning (Joughin, 2007; Sundrarajun \& Kiely, 2010). It contributes to improving linguistic ability, building confidence, acquiring subject-specific knowledge, developing interpersonal and collaborative skills, refining presentation skills, socializing students into the academic context, and increasing creativity and problem-solving ability (Morita, 2000; Usher, 2002; Kobayashi, 2003; Zappa-Hollman, 2007; Sundrarajun \& Kiely, 2010; Chou, 2011).

In teaching EFL students to make OPs as a situated task, the above skills serve as a reference for formulating teaching objectives. To scaffold students' skill acquisition, $\mathrm{SR}$ is one of the most important steps in instructional design.

\subsection{Situated learning and self-reflection}

Experiential learning theory (Schön, 1983; Kolb, 1984) highlights that effective learning lies in the process of grasping experience of accomplishing a meaningful goal and transforming this experience into knowledge. The experiential learning model goes through a cyclical pattern of four phases: concrete experience during which learners complete a situated task, reflective observation in which learners reflect on what is done and consider what is working and what is not, abstract conceptualization where they think of ways to improve, and active experimentation where they make new attempts to try it again based on previous experience, reflection, and new conceptions.

Learners grasp the information from the situated learning experience phase which forms the basis for reflection. Reflection serves as the basis for conceptualization, which then leads to growth in new knowledge about the world. Learners then experiment with the new knowledge and the new cycle of experiential learning starts all over again. Schön (1983) defines professionals as those who link knowing and doing through reflection. Kolb (1984) argues for the importance of reflection by contending that only when professionals reflect on their learning can they develop theoretical understanding of it, apply new knowledge to new situations, and keep reframing and modifying their knowledge. It is learners' consecutive SRs that lead them to generate a change in conceptual perspectives (Schön, 1983; Kolb, 1984). 
The pedagogical implication of the experiential learning theory is that instructors should provide situated learning opportunities for learners by creating real-world scenarios (Kolb, 1984), and guide and encourage them to make reflections to support their growth of knowledge (Joyce, Calhoun \& Hopkins, 2002; Smith, 2011).

In teaching OPs, learners' SRs can take various forms. Viewing video recordings of their own OPs is one of them.

\subsection{Video recording as a pedagogical tool}

Video recording is a widely-used pedagogical tool in teacher education. Teacher education scholars see video recordings of students' teaching practice as reliable sources for students to make SRs (Robinson \& Kelley, 2007; van Es, Tunney, Goldsmith \& Seago, 2014).

Literature on teacher education indicates that the support of video recordings of their own teaching practice helps improve students' performance. Video recordings can help students analyze and evaluate their teaching practice from an observer's stance (Kong, Shroff \& Hung, 2009), stimulate them to externalize their reflective ideas on their teaching practice with evidence (Calandra, Brantley-Dias, Lee \& Fox, 2009; Kong et al. 2009; Rich \& Hannafin, 2009), contribute to the quantity, depth, and quality of their SRs (Robinson \& Kelley, 2007; Sönmez \& Hakverdi-Can, 2012; Baecher, Kung, Jewkes \& Rosalia, 2013; van Es et al., 2014), and allow them to actively construct new insights and be responsible for themselves in learning (Cherrington \& Loveridge, 2014). As a result, student teachers make improvement in their practice (Dawson et al., 2001; Shepherd \& Hannafin, 2008; Tripp \& Rich, 2012a; McFadden et al., 2014).

Although video recording is widely used in teacher education, it is a rare pedagogical practice in teaching OPs, as is evidenced by a recent state of the art review (van Ginkel, Gulikers, Biemans \& Mulder 2015). Barry (2012) and Murphy and Barry (2016) investigated students' perception of video recording and viewing of presentations within an Australian university and found that viewing and then reflecting on videos of group presentations was an effective way of feedback and could improve students' performance. So far, the use of videos to assist students' SRs on their OP experiences in EFL contexts is still an under-researched area. The effectiveness and students' perceptions of this pedagogical intervention are not known yet. This study is concerned with the use of VASRs in teaching OP skills to first-year undergraduates in an EFL context. 


\section{Methodology}

\subsection{Research design}

Using a quasi-experimental two-group pre-test post-test comparison design, this study aims at answering two questions: how effective is VASR in teaching EFL students to make OPs?' and 'how do students perceive the pedagogical use of VASRs?'

A self-assessment (SA) questionnaire was used to test the two groups' baseline competence as the pre-test at the very beginning of OP teaching. Differentiated instructional designs were then applied to the control and experimental group. While the two groups received instructions regarding the same content from the same instructor (researcher) in the same classroom, they differed in one important procedure. The experimental group made SRs by viewing video recordings of their OPs for about 14 weeks, while the control group did not. The same SA questionnaire was used to test the two group's OP skills as the post-test at the end of OP teaching. The gains between the pre-test and post-test offered evidence to research question one.

Another questionnaire with open-ended questions was completed only by the experimental group towards the end of OP teaching for students to reflect on their experiences of VASRs. Data from this questionnaire were used to answer research question two.

\subsection{Context and participants}

This study was conducted at a university in China. In the local context, all learners are non-native speakers of English. On the one hand, they need to use English to communicate in public, which requires them to be active and sociable learners. On the other hand, given the impact of Confucian traditions, they favor a teacher-centered classroom and are more silent and passive. Therefore, OP is a very challenging task for them since it may cause anxiety, nervousness, and lack of confidence. However, it is also a way to improve their linguistic ability, build confidence, and develop interpersonal skills.

Participants were 29 undergraduates. They were assigned randomly into the experimental group $(n=14)$ and control group $(n=15)$. There were 6 males and 23 females with an average age of 19. As first-year English learners, they were learning English as a foreign language within a Bachelor of Translation degree program. They were all admitted based on their academic achievement in university entrance examination and took courses within the same curriculum. When the current research was administered, they were undertaking a comprehensive English course aimed at 
improving their overall communicative competence. Before taking the course, most of them had never had any prior OP experiences.

\subsection{Instructional design}

OP was not a separate course in the context concerned, but one of the most important oral activities in an English course to enhance students' communicative competence. In the first semester of their first year, the course consisted of six units on six topics related to international and domestic current affairs. In each unit, the students were asked to make group OPs towards the conclusion of the unit. The OPs were designed as situated tasks because the students went through an experiential learning cycle. They gained concrete learning experiences in real-world OP scenarios, made VASRs, and thought of ways to improve before taking new action to try the next OP task. The seven-step instructional procedures, including pre-, during- and post-tasks, are displayed in Table 1. As shown in the table, the control group and experimental group received differentiated instructions because they differed in the last step, VASRs, which was the focus of the current research. The instructional design involved six OPs, one in each unit. Five of all students' six OPs (except the first one) were recorded. 
Table 1. Instructional procedures for the two groups.

\begin{tabular}{|c|c|c|c|}
\hline \multicolumn{2}{|c|}{$\begin{array}{l}\text { Instructional } \\
\text { procedures }\end{array}$} & \multirow{2}{*}{$\begin{array}{l}\text { Control group } \\
\text { The students read two background texts on the } \\
\text { topic of the unit to stimulate their interest and } \\
\text { activate their prior knowledge. }\end{array}$} & Experimental group \\
\hline Pre-task & Starter & & \multirow{6}{*}{$\begin{array}{l}\text { The same as the control } \\
\text { group. }\end{array}$} \\
\hline & $\begin{array}{l}\text { Input of } \\
\text { language } \\
\text { and } \\
\text { knowledge }\end{array}$ & $\begin{array}{l}\text { With scaffolding from the instructor, the } \\
\text { students discussed three texts and watched } \\
\text { video clips on the topic through various } \\
\text { teaching activities to learn language forms and } \\
\text { acquire relevant knowledge. }\end{array}$ & \\
\hline & $\begin{array}{l}\text { Mind } \\
\text { mapping }\end{array}$ & $\begin{array}{l}\text { The students did mind mapping exercises to } \\
\text { review the ideas and sub-ideas of all texts in the } \\
\text { unit, paving the way for the upcoming OP task. }\end{array}$ & \\
\hline & Briefing & $\begin{array}{l}\text { The instructor informed students of the details } \\
\text { of the presentation task which asked them to } \\
\text { take the roles of certain speakers in a simulated } \\
\text { communicative context. }\end{array}$ & \\
\hline $\begin{array}{l}\text { During- } \\
\text { task }\end{array}$ & $\mathrm{OP}$ & $\begin{array}{l}\text { The students took turns to make presentations } \\
\text { in a classroom equipped with computers and } \\
\text { projectors, while the instructor and students } \\
\text { who were not making presentations served as } \\
\text { audience. Their performances were recorded by } \\
\text { students who volunteered as the camera } \\
\text { operators. }\end{array}$ & \\
\hline \multirow[t]{2}{*}{$\begin{array}{l}\text { Post- } \\
\text { task }\end{array}$} & Debriefing & $\begin{array}{l}\text { Shortly after the presentations, the instructor } \\
\text { commented on students' performance and gave } \\
\text { feedback. Those who needed additional help } \\
\text { were asked to approach the instructor } \\
\text { individually. }\end{array}$ & \\
\hline & VASRs & $\begin{array}{l}\text { This procedure did not apply to the control } \\
\text { group. }\end{array}$ & $\begin{array}{l}\text { The students in the } \\
\text { experimental group were } \\
\text { asked to view video } \\
\text { recordings of their OPs } \\
\text { and make SRs after class, } \\
\text { as an assignment. They } \\
\text { were told to reflect on } \\
\text { their performance but no } \\
\text { protocols were given to } \\
\text { guide their reflections. }\end{array}$ \\
\hline
\end{tabular}

Although OP demands a lot of skill from presenters, as mentioned previously, only some of the skills were involved in this study. OP was designed as an instructional activity to help the students achieve seven objectives, all relating to students' ability to perform certain functions in English in specific communicative contexts. Before the participants made their first OPs at the beginning of the semester, they attended an orientation class to make sure that they had a clear understanding of what each objective meant. Those objectives were concerned with seven OP skills:

1. Research and documentation: to investigate the OP theme by using internet and library resources when preparing OPs; 
2. Oral expression: to express oneself clearly, correctly and fluently when delivering OPs (with acceptable pronunciation, stress, and intonation and with very few grammatical errors, incorrect or excessive use of spoken emphasis, fillers, repetitions, pauses, and false starts);

3. Logical thinking: to make convincing arguments with a coherent train of thought and appropriate evidence when delivering OPs;

4. Use of non-verbal elements: to use eye contact, facial expression, hand movement, and body posture appropriately when delivering OPs;

5. Knowledge: to display adequate knowledge of the OP theme when delivering OPs;

6. Psychological quality: to stay calm and show self-confidence when delivering OPs;

7. Team work: to collaborate effectively with team members to decide what and how to present when preparing OPs.

\subsection{Instruments}

Two questionnaires were used in the present study: 'Questionnaire A. SA of OP Skills' and 'Questionnaire B. Perceptions on the Use of VASRs'. Both were developed and then revised for comprehension and clarity, following suggestions from colleagues.

Questionnaire A consisted of seven statements, each corresponding to one of the seven targeted skills: research and documentation, oral expression, logical thinking, use of non-verbal elements, knowledge, psychological quality, and team work. Students rated their achievement on each of the skills on a four-point Likert scale (1 strongly disagree, 2 disagree, 3 agree, and 4 strongly agree). The 'forced choice' scaling method was used, with the 'neutral' option removed. This is because the neutral option is an easy option to take when a student is not sure about which one to choose. When a 'neutral' option is selected, it may mean 'undecided' instead of 'neither agree nor disagree'.

Questionnaire B included three open-ended questions. The first one asked what students focused on when they were viewing video recordings of their OPs. The second was concerned with two issues: if viewing recordings of their OPs was helpful, and in what aspects they made progress because of viewing recordings of their OPs. The third one asked which was more helpful in improving their OP skills -the instructor's feedback in the debriefing session or viewing recordings of their OPs, and in what ways they complemented each other.

It needs to be pointed out that SA has been identified as a valid indirect measure of students' achievement, although researchers are unsure of its suitability as a proxy for objective standardized measures. Learners' SA of skills reflects their self-efficacy 
(beliefs in their ability to accomplish a task) which guides their efforts and persistence in learning (Bandura, 1993). Research in many subject areas suggests that results of students' SA of learning outcomes correlate positively with those of instructors' direct external measures and that students' self-reported rating of learning is an important indicant of learning achievement (Falchikov \& Boud, 1989; Chesebro \& McCroskey, 2000; Shen, 2002; Marks, Fairris \& Beleche, 2012; Benton, Duchon \& Pallett, 2013). In a recent study on the validity of SA in language teaching, Brown, Dewey and Cox (2014) conclude that students' SA of learning outcomes can be high in reliability and offer valuable information on their perceived achievement, supporting findings of previous language assessment research that $\mathrm{SA}$ and standardized tests are positively correlated (see Bachman \& Palmer, 1989; Alderson, 2005; Alexandria, 2009; Brantmeier, Vanderplank \& Strube, 2012; Préfontaine, 2013; Lappin-Fortin \& Rye, 2014). Though students' learning outcomes can be ideally assessed by combining SA and direct measures, composing and administrating direct measures for each of the seven teaching objectives is time-consuming, costly, and impractical for the current study. Therefore, students' progress in each objective was assessed through SA questionnaires.

\subsection{Procedure}

Before involving students in the current research project, the researcher obtained their consent to be participants. They were told that they would participate in a research project on a voluntary basis, that their responses would not have any effect on their grades, that their identities would remain anonymous, and that results may help them improve their learning efficiency.

The present study consisted of four phases. Questionnaire A was administered as the pre-test for the participants to rate their competence in each of the seven OP skills when they had immediately finished their first OPs at the beginning of the semester. Then the differentiated instruction was implemented to the control and experimental group as shown in Table 1, for about 14 weeks. Subsequently, questionnaire A was administered again as the post-test when the participants had immediately finished their last OPs, towards the conclusion of the course. After the post-test, questionnaire $\mathrm{B}$ was completed only by the experimental group.

Data collected through questionnaire A were analyzed using SPSS 16.0 for Windows. With Cronbach's alpha $(\alpha)$ values of .796 and .918 (for the pre-test and post-test respectively), it has good internal consistency reliability. SPSS GLM was used to perform a univariate analysis of covariance (ANCOVA). The differentiated instructions received by the two groups were used as an independent variable. Students' post-test on their seven OP skills was used as the dependent variable. The ANCOVA was run to examine if the dependent variable impacted the independent variable, using the pre-test results as a covariate to control initial differences in the 
seven skills. Preliminary checks were performed to determine if statistical assumptions were violated in the dataset for ANCOVA, such as normality, reliable measurement of covariance, and homogeneity of variance. The results of between-subjects effect tests showed that the assumptions were satisfied $(F=.033, p=.857 ; F=.711, p=.407 ; F$ $=.272, p=.607 ; F=2.936, p=.099 ; F=.000, p=1.000 ; F=.468, p=.500 ; F=.010$, $p=.921)$.

Data from questionnaire B were analyzed in accordance with the steps recommended by Creswell (2014): organizing and preparing the data, reading through the information, coding the data, developing a thematic analysis from the codes, and presenting findings in tables before interpreting them. Two broad categories of themes were identified, one related to use of non-verbal elements including eye contact, facial expression, hand movement, and body posture, while the other concerned oral expression (pronunciation, voice projection, fluency, and intonation).

\section{Results, discussion, and implications}

\subsection{The effectiveness of VASR}

The first research question was how effective VASRs were in teaching EFL students to make OPs.

Table 2. Means and standard deviations for pre-test and post-test scores.

\begin{tabular}{|l|l|l|l|l|l|c|c|}
\hline \multicolumn{2}{|c|}{ Measure } & \multicolumn{2}{c|}{ M } & \multicolumn{2}{c|}{ SD } & \multicolumn{2}{c|}{ N } \\
\cline { 3 - 8 } & $\begin{array}{c}\text { Ctrl } \\
\text { group }\end{array}$ & $\begin{array}{c}\text { Exp } \\
\text { group }\end{array}$ & $\begin{array}{c}\text { Ctrl } \\
\text { group }\end{array}$ & $\begin{array}{c}\text { Exp } \\
\text { group }\end{array}$ & $\begin{array}{c}\text { Ctrl } \\
\text { group }\end{array}$ & $\begin{array}{c}\text { Exp } \\
\text { group }\end{array}$ \\
\hline \multirow{2}{*}{ Oral expression } & Pre-test & 1.8000 & 2.2857 & .77460 & .91387 & 15 & 14 \\
\cline { 2 - 8 } & Post-test & 2.8667 & 3.2143 & .63994 & .69929 & 15 & 14 \\
\hline \multirow{2}{*}{ Critical thinking } & Pre-test & 1.8667 & 2.0714 & .63994 & .82874 & 15 & 14 \\
\cline { 2 - 8 } & Post-test & 3.1333 & 3.2143 & .83381 & .69929 & 15 & 14 \\
\hline $\begin{array}{l}\text { Use of non-verbal } \\
\text { elements }\end{array}$ & Pre-test & 2.2000 & 2.4286 & .77460 & .64621 & 15 & 14 \\
\cline { 2 - 8 } $\begin{array}{l}\text { Research and } \\
\text { documentation }\end{array}$ & Post-test & 3.1333 & 3.5714 & .51640 & .51355 & 15 & 14 \\
\hline \multirow{2}{*}{ Knowledge } & Pre-test & 2.7333 & 2.7143 & .79881 & .72627 & 15 & 14 \\
\cline { 2 - 8 } & Post-test & 3.2000 & 3.3571 & .77460 & .84190 & 15 & 14 \\
\cline { 2 - 7 } & Pre-test & 2.0000 & 2.2857 & .37796 & .72627 & 15 & 14 \\
\hline quality & Post-test & 3.2000 & 3.3571 & .56061 & .84190 & 15 & 14 \\
\cline { 2 - 7 } Team work & Pre-test & 1.9333 & 2.4286 & .79881 & .75593 & 15 & 14 \\
\cline { 2 - 7 } & Post-test & 2.8667 & 3.3571 & .51640 & .84190 & 15 & 14 \\
\cline { 2 - 7 } & Pre-test & 2.4667 & 2.9286 & .63994 & .47463 & 15 & 14 \\
\hline
\end{tabular}

Table 2 shows the number of participants, mean, and standard deviation of the two groups' scores on the seven OP skills in the pre-test and post-test. As displayed, in the post-test both groups obtained higher scores than they did in the pre-test, suggesting that both groups made progress in the seven skills, although the two groups received differentiated instructions. 
Table 3. Results of ANCOVA on post-test using pre-test as a covariate.

\begin{tabular}{|l|l|l|l|l|l|l|}
\hline \multicolumn{1}{|c|}{ Measure } & \multicolumn{1}{|c|}{ Source } & \multicolumn{1}{c|}{$\boldsymbol{d f}$} & Mean Square & \multicolumn{1}{c|}{$\boldsymbol{F}$} & \multicolumn{1}{c|}{$\boldsymbol{p}$} & \multicolumn{1}{c|}{$\boldsymbol{\eta}^{2}$} \\
\hline Oral expression & group & 1 & .719 & 1.551 & .224 & .056 \\
\hline Critical thinking & group & 1 & .046 & .074 & .788 & .003 \\
\hline Use of non-verbal elements & group & 1 & 1.335 & 4.894 & $.037 *$ & .157 \\
\hline Research and documentation & group & 1 & .191 & .301 & .588 & .011 \\
\hline Knowledge & group & 1 & .611 & 1.393 & .249 & .051 \\
\hline Psychological quality & group & 1 & 1.625 & 3.265 & .082 & .112 \\
\hline Team work & group & 1 & .019 & .045 & .833 & .002 \\
\hline
\end{tabular}

Table 3 presents the ANCOVA results on the post-test with the pre-test scores as the covariate. As is evidenced, for the use of non-verbal elements, the two groups showed a statistically significant difference $\left(F=4.894, \eta^{2}=.157, p=.037\right)$, suggesting that VASRs resulted in the variance in the use of non-verbal elements between the two groups. For the other six skills, the two classes did not demonstrate statistically significant differences, suggesting that the effect of VASRs was not evident.

In sum, after running descriptive and inferential statistics, two findings were noted. Firstly, although only the experimental group viewed recordings of their own OPs and made SRs, both groups made progress in all of the seven skills. Secondly, VASRs was effective in developing students' skill in using non-verbal elements. Its effect in the other six skills was not evident.

The findings contribute to knowledge on the pedagogical value of OPs. The finding that both groups made progress in the seven skills supports the literature that OPs help students improve linguistic ability, build confidence, acquire subject-specific knowledge, and develop interpersonal and collaborative skills (Morita, 2000; Usher, 2002; Kobayashi, 2003; Zappa-Hollman, 2007; Sundrarajun \& Kiely, 2010; Chou, 2011). Although only the experimental group made VASRs, both groups followed the same procedures including starter, input, mind mapping, briefing, OP, and debriefing. In the debriefing session, the instructor provided feedback to both groups, highlighting their strengths and weaknesses. Therefore, both groups might have made progress because of their own efforts in preparing and delivering OPs and the help of the instructor's feedback. Students' improvement in skill may have been influenced more by obtaining feedback from their instructors than by VASRs. This is consistent with previous research which supports students' preference and confidence concerning the usefulness of instructors' feedback (Halter, 2006; Rich \& Hannafin, 2008; Tripp \& Rich, 2012b).

The current findings also add knowledge to the literature that VASRs is effective in teaching EFL students to make OPs, though its effect is limited to non-verbal skills. The effect was very limited, compared with findings of research on teacher education 
that it contributes to student teachers' improvement in their teaching practice (Dawson et al., 2001; Shepherd \& Hannafin, 2008; Tripp \& Rich, 2012a; McFadden et al., 2014).

What might have been responsible for the limited effects of VASR? One possible explanation is that a well-established protocol was not provided to the students in the experimental group to make SRs on their recorded OPs. On the one hand, the students in the current study were in a teacher-centered culture where learners are passive and silent and expect the instructor to shoulder more responsibilities (Watkins \& Biggs, 2001; Woodrow, 2006; Bankowski, 2010). On the other hand, the instructor did not provide any protocol for the students to follow in their SRs. Research on teacher education finds that students observing their own videos of performance require more scaffolding than observing videos of others' performance (Kleinknecht \& Schneider, 2013). Prior research has identified the benefits of a systematic SR protocol to facilitate students to notice certain aspects of their performances (Zeichner \& Tabachnick, 1991; Collins, Cook-Cottone, Robinson \& Sullivan, 2004; van Es et al., 2014). With a protocol, students' SRs are of better quality (Fox, BrantleyDias \& Calandra, 2007), while without it students tend to concentrate on non-verbal elements (Calandra, Gurvitch \& Lund, 2008; McFadden et al., 2014; van Es et al., 2014) and lack a critical stance (Cherrington \& Loveridge, 2014). It has also been indicated that, besides learners' observation of their own behaviors, their progress requires the assistance of an external facilitator who interprets their current behaviors and provides alternatives in terms of better practice (Timperley \& Robinson, 2001). Since the students in the experimental group were not provided with any protocol to assist their SRs, their concentration might have been primarily placed on non-verbal elements -for example, how they behaved in the video (non-verbal elements) - and ignored other aspects such as oral expression, logical thinking, knowledge, and so on.

Another factor that might have limited the effect of VASRs is the nature of some of the skills. Some skills, such as research, documentation, and team work, though they can be reflected in the final product of their OPs, took place in the preparation phase before their OPs. Problems in those regards are much more difficult to trace in the videos. Therefore, students' SR might ignore those areas.

One implication of the current findings is that the instructor should provide a collaborative reflection protocol to prescribe what students and their instructor are supposed to focus on in making SRs and giving feedback respectively. The protocol can take various forms. For example, checklists can help students narrow their focus and gain more knowledge (Prusak, Dye, Graham \& Graser, 2010). Essays, journal writing, notes, questionnaire responses and other forms of written reflection also help students produce more focused and accurate reflection (Welsch \& Devlin, 2004; Rich \& Hannafin, 2008; Shepherd \& Hannafin, 2009). Additionally, video editing, 
conferences, and interviews are useful tasks that students can engage in to aid their SRs (Tripp \& Rich, 2012a). However, the instructor should be cautious in formulating the protocol. Although a checklist facilitates reflection, instructors may have difficulties in deciding how many items should be listed in the checklist (Prusak et al., 2010). It is more effective for students to focus on a subset of the protocol, because they may feel overwhelmed and find it less helpful in VASR when the checklist includes too many items (Tripp \& Rich, 2012a). Students prefer to decide and concentrate on their own list of criteria in their SRs (Rich \& Hannafin, 2008). It is advisable for the instructor to provide a well-structured protocol to facilitate students and to allow them to have their own foci of reflection (Tripp \& Rich, 2012a).

\subsection{Students' perceptions of VASR}

The second research question was about students' perception of VASRs. Data from questionnaire B were analyzed and classified under different headings, along with their frequencies. Students' answers were quoted as evidence.

Table 4. Focus of students' SRs.

\begin{tabular}{|c|c|c|c|}
\hline \multicolumn{2}{|r|}{ Category } & \multicolumn{2}{|c|}{ Frequency } \\
\hline \multirow[t]{4}{*}{ Non-verbal element } & Eye contact & 6 & \multirow[t]{4}{*}{15} \\
\hline & Body posture & 3 & \\
\hline & Hand movement & 3 & \\
\hline & Facial expression & 3 & \\
\hline \multirow[t]{4}{*}{ Oral expression } & Voice projection & 5 & \multirow[t]{4}{*}{12} \\
\hline & Pronunciation & 4 & \\
\hline & Intonation & 2 & \\
\hline & General comments on oral expression & 1 & \\
\hline
\end{tabular}

What did the students in the experimental group focus on when they made VASRs? Table 4 presents the categories of students' foci and their frequencies. The 14 students in the experimental group reflected on two broad categories of problems. The non-verbal element category was mentioned 15 times, while oral expression was mentioned 12 times. These can be evidenced from students' answers:

"When viewing videos of my OPs, I mainly concentrated on my voice and eye contact. I seldom paid attention to other aspects" (Student $\mathrm{NDN}$ ).

"I examined how I behaved in the presentations. I also paid attention to my language quality. Well, the former always attracted more of my attention" (Student SM).

Was viewing videos of their OPs helpful? In what aspects had they made progress because of the VASR experience? All 14 students expressed the view that viewing videos of their own OPs was helpful. As shown in Table 5, they attributed their 
progress in the use of non-verbal elements (mentioned 13 times) and oral expression (mentioned 7 times) to their experience of viewing videos of their OPs, as can be seen from their answers to the question:

"Viewing videos of my own presentations was helpful. I could see my weaknesses directly from the perspective of the audience, in particular non-verbal elements, for example, use of voice, facial expression, and body posture. It might be an exaggeration to say that I made strides in them after I first noticed them, but I did pay close attention to them the next time I made Ops" (Student JBL).

"It was helpful indeed. By watching myself in videos, I could see my problems and make corrections. I think I made progress in voice projection and body language/posture. My oral expression also improved a lot, especially in fluency. There used to be a lot of long pauses and fillers ('en' or 'euh') in my presentations. After viewing the video several times, I am much better in this regard" (Student LT).

Table 5. Areas in which students progressed because of VASRs.

\begin{tabular}{|l|l|l|l|}
\hline \multicolumn{2}{|c|}{ Category } & \multicolumn{2}{|c|}{ Frequency } \\
\hline \multirow{4}{*}{ Non-verbal element } & Body posture & 5 & \multicolumn{1}{|c|}{13} \\
\cline { 2 - 3 } & Eye contact & 4 & \\
\cline { 2 - 3 } & Hand movement & 2 & \\
\cline { 2 - 3 } & Facial expression & 2 & \\
\hline \multirow{3}{*}{ Oral expression } & Voice projection & 4 & 7 \\
\cline { 2 - 3 } & Intonation & 2 & \\
\cline { 2 - 3 } & Fluency & 1 & \\
\hline
\end{tabular}

Based on analysis of the students' answers, it can be concluded that students primarily focused on their use of non-verbal elements and oral expression in OPs while making VASRs, and that it was in the former area that VASRs were effective. The results indicated that VASRs were effective in helping students make progress in the use of non-verbal elements, which is consistent with the results of previous research where no protocols were provided to guide students' SRs (Timperley \& Robinson, 2001; Calandra et al., 2008; Cherrington \& Loveridge, 2014; McFadden et al., 2014). This finding concurs with the results of quantitative analysis in the previous section that the use of video recordings was only effective in developing students' skill in using non-verbal elements. The agreement between the quantitative and qualitative data pointed to the necessity of a systematic protocol to scaffold students to ensure the quality of their SRs (Zeichner \& Tabachnick, 1991; Collins et al., 2004).

Which was more helpful in improving their OP skills, the instructor's feedback in the debriefing session or viewing videos of their OPs? In what ways can they complement each other? Students' responses indicated that they benefited from both the instructor's feedback and VASRs, which complemented each other. 
Of the 14 students, seven indicated that feedback and VASRs were equally helpful; four thought the instructor's feedback was more helpful; and three rated VASRs as more helpful. All students suggested that the instructor's feedback and VASRs had different advantages. The instructor's feedback was more systematic and in-depth because it covered all presentation-related aspects, particularly weaknesses that students could hardly see by themselves, such as logic and content, and gave suggestions for further improvement. By contrast, in VASR, students tended to have a narrowed focus, concentrating on non-verbal skills, such as hand movement, eye contact, and body posture.

According to students' responses, SRs were very good supplementary sources of information for two reasons. Firstly, although the instructor gave feedback concerning the non-verbal skills of their OPs, the feedback was not impressive because they could not directly see their weaknesses at the moment of being given feedback. The use of VASRs, however, allowed students to view their performance from the perspective of the audience. Such a perspective was more direct and impressive for them, helping them to better understand the non-verbal elements of their presentations. This was evidenced by students' answers:

“I had gains from both experiences. The teacher' feedback was helpful because he commented on language quality and organization of ideas. SR with videos was also beneficial because I could obtain information that was not present in the feedback. I could view my performance from an observer perspective. For example, I could see that my hand movements distracted the audience. I could also check if I had made eye contact with the audience and even calculate the times of my eye contact" (Student HXX).

"The teacher's feedback helped me see weaknesses that I failed to notice; for example, logic. When viewing videos of my own OPs, I could hardly notice other problems except for directly visible issues, such as my use of voice, eye contact, and body position. The advantage of videos was that it presented the 'hard facts' in front of my eyes" (Student NDN).

"Both feedback and SR were necessary. The benefits of VASR were that I could see myself making presentations live in videos. I could see vividly how I behaved on the stage and interacted with the audience, and notice my inappropriate behaviors. The teacher's feedback focused on all aspects, including non-verbal skills, content, logic, and many others. Without it, I might have never realized my weaknesses in logic. I think it is necessary to combine the two" (Student SM).

Secondly, the use of VASRs provided an unlimited access for reflection. The instructor's oral feedback did not allow for future review. However, videos could be reviewed for as many times as wanted, as was pointed out by one student: 
"I learned from both the teacher's feedback and viewing videos. The feedback was more inclusive. Viewing videos of my presentations was more individual-specific. I could view them repeatedly and freely" (Student GMZ).

The results presented here support the literature that video recordings can help students analyze and evaluate their own performance as observers (Kong et al., 2009) and externalize ideas on their competence (Calandra et al., 2009; Kong et al., 2009; Rich \& Hannafin, 2009), and that students may have a preference for and confidence in instructors' feedback (Halter, 2006; Rich \& Hannafin, 2008; Tripp \& Rich, 2012b).

The findings of the current study are meaningful in that so far there have been very few contributions on the effect of VASRs in teaching OPs in EFL contexts. This study shows that videos contribute to the quality of students' SRs (Robinson \& Kelley, 2007; Sönmez \& Hakverdi-Can, 2012; Baecher et al., 2013) by providing students with information to evaluate their English OPs from the perspective of observers (Kong et al., 2009) and externalizing evidence of their competence (Calandra et al., 2009; Kong et al., 2009; Rich \& Hannafin, 2009). This study thus shows the effectiveness of VASRs in teaching EFL students to make OPs. Moreover, it reveals the weaknesses of VASRs without external guidance and points to the necessity of a well-structured protocol to increase the quality of students' SRs (Zeichner \& Tabachnick, 1991; Collins et al., 2004). Additionally, it shows the complimentary role of VASRs to instructors' feedback which students still prefer and trust (Halter, 2006; Rich \& Hannafin, 2008; Tripp \& Rich, 2012b). The finding, that students' limited progress in their English OPs as a result of VASRs could be improved by means of a wellstructured protocol and the instructor's feedback, also provides evidence to the effectiveness of teaching English OP according to the philosophy of experiential learning: that learners' growth of knowledge depends on the instructor's guidance to reflect on their experience (Joyce et al., 2002).

Based on the advantages and complimentary role of VASRs, the pedagogical implication is that both the instructor's feedback and VASRs are necessary in teaching OPs. When students finish their OPs, the instructor should provide feedback during debriefing and guide students to make VASRs with the help of a focused protocol as discussed above.

\section{CONCLUSIONS}

The present study aimed at investigating the effectiveness of VASR in teaching EFL students to make OPs and students' perceptions of the pedagogical use of VASRs.

Two preliminary findings were made. Firstly, according to the ANCOVA results on the post-test with the pre-test scores as the covariate, the experimental and control 
groups showed a statistically significant difference in the use of non-verbal elements, suggesting that VASR was effective in improving students' use of non-verbal elements. That the effect of VASR was limited in the present study might have been because no systematic protocols were formulated to guide students' SRs.

Secondly, based on the analysis results of students' response to the open-ended questions, they perceived VASRs as beneficial activities. They reported that they benefited from VASRs as well as the instructor's feedback, which are complimentary to each other because each has its own advantages. Due to the lack of a systematic protocol, they primarily focused on the use of non-verbal elements and oral expressions while making VASRs, and thus made more progress in the former. Pedagogically, a systematic protocol would be necessary to guide students in making VASRs so that they can increase depth and quality. In addition, VASRs should be combined with instructor feedback to achieve a better learning effect.

Given the limitations, the findings from this study should be treated with caution. Firstly, the researcher was the instructor of both the control and experimental groups, which had the potential to cause bias in interpreting the data. Secondly, the generalizability of the current findings to other contexts may have been affected by the fact that the number of participants was small and they all belonged to the same teaching context. Thirdly, the current research used an indirect measure (that is, the SA questionnaire) as the primary data collection method. Although the results of the qualitative data paralleled those of the quantitative data, and previous research has identified that students' SA of their achievement is positively correlated with the results of external measures (Alexandria, 2009; Brantmeier et al., 2012; Marks et al., 2012; Benton et al., 2013; Préfontaine, 2013; Brown et al., 2014; Lappin-Fortin \& Rye, 2014), more direct and multiple measures could have produced data to triangulate the current findings. Since composing and administering separate direct measures to assess students' competence in each of the seven presentation skills would have been very time-consuming and costly, efforts may be devoted to exploring the effect of using systematic protocols to guide students' VASRs through data triangulation in any follow-up research.

\section{REFERENCES}

Adams, K. (2004). Modeling success: Enhancing international postgraduate research students' self-efficacy for research seminar presentations. Higher Education Research \& Development, 23, 115-130.

Alderson, C. (2005). Diagnosing foreign language proficiency. London: Continuum.

Alexandria, W. (2009). Adult English learners' self assessment of second language proficiency: Contexts and conditions. New York: New York University Press. 
Bachman, L. F. \& Palmer, A. S. (1989). The construct validation of self-ratings of communicative language ability. Language Testing, 6, 14-29.

Baecher, L., Kung, S. C., Jewkes, A. M. \& Rosalia, C. (2013). The role of video for self evaluation in early field experiences. Teaching and Teacher Education, 36, 189197.

Bandura, A. (1993). Perceived self-efficacy in cognitive development and functioning. Educational Psychologist, 28, 117-148.

Bankowski, E. (2010). Developing skills for effective academic presentations in EAP. International Journal of Teaching and Learning in Higher Education, 22, 187-196.

Barry, S. (2012). A video recording and viewing protocol for student group presentations. Computers \& Education, 59, 855-860.

Benton, S. L., Duchon, D. \& Pallett, W. H. (2013). Validity of student self-reported ratings of learning. Assessment and Evaluation in Higher Education, 38, 377-388.

Brantmeier, C., Vanderplank, R. \& Strube, M. (2012). What about me? Individual self assessment by skill and level of language instruction. System, 40, 144-160.

Brown, N. A., Dewey, D. P. \& Cox, T. L. (2014). Assessing the validity of can-do statements in retrospective (then-now) self assessment. Foreign Language Annals, 47, 261-285.

Calandra, B., Gurvitch, R. \& Lund, J. (2008). An exploratory study of digital video editing as a tool for teacher preparation. Journal of Technology and Teacher Education, 16, 137-153.

Calandra, B., Brantley-Dias, L., Lee, J. K. \& Fox, D. L. (2009). Using video editing to cultivate novice teachers' practice. Journal of Research on Technology in Education, 42, 73-94.

Campbell, K., Mothersbaugh, D., Brammer, C. \& Taylor, T. (2001). Peer versus self assessment of oral business presentation performance. Business Communication Quarterly, 64, 23-42.

Chen, L. (2009). A study of EFL graduate students' oral presentation anxiety. Unpublished master thesis, National Chung Cheng University, Taiwan, China.

Cheng, W. \& Warren, M. (2005). Peer assessment of language proficiency. Language Testing, 22, 93-121.

Cherrington, S. \& Loveridge, J. (2014). Using video to promote early childhood teachers' thinking and reflection. Teaching and Teacher Education, 41, 42-51. 
Chesebro, J. L. \& McCroskey, J. C. (2000). The relationship between students' reports of learning and their actual recall of lecture material. Communication Education, 49, 297-301.

Chou, M. (2011). The influence of learner strategies on oral presentations. English for Specific Purposes, 30, 272-285.

Collins, J. L., Cook-Cottone, C. P., Robinson, J. S. \& Sullivan, R. R. (2004). Technology and new directions in professional development. Journal of Educational Technology Systems, 33, 131-146.

Creswell, J. W. (2014). Research design: Qualitative, quantitative, and mixed methods approaches (4th ed.). London: Sage.

Dawson, P. J., Dawson, K. E. \& Forness, S. R. (2001). Effect of video feedback on teacher behavior. Journal of Educational Research, 68, 197-201.

De Grez, L., Valcke, M. \& Roozen, I. (2014). The differential impact of observational learning and practice-based learning on the development of oral presentation skills in higher education. Higher Education Research \& Development, 33, 256-271.

Falchikov, N. \& Boud, D. (1989). Student self-assessment in higher education. Review of Educational Research, 59, 395-430.

Fox, D. L., Brantley-Dias, L. \& Calandra, B. (2007). Promoting preservice teachers' reflective practice through digital video and critical incident analysis in secondary English education. Paper presented at the $57^{\text {th }}$ National Reading Conference, Austin, USA.

Halter, C. P. (2006). The reflective lens: The effects of video analysis on preservice teacher development. Unpublished EdD dissertation, University of California, California, USA.

Hill, M. \& Storey, A. (2003). SpeakEasy: Online support for oral presentation skills. ELT Journal, 57, 370-376.

Jeon, J. (2005). A study on oral presentation anxiety and confidence. The Journal of Asia TEFL, 2, 89-115.

Joughin, G. (2007). Student conceptions of oral presentations. Studies in Higher Education, 32, 323-336.

Joyce, B., Calhoun, E. \& Hopkins, D. (2002). Models of learning: Tools for teaching (2nd ed.). Buckingham, UK: Open University Press. 
Kibler, A. K., Salerno, A. S. \& Palacios, N. (2014). But before I go to my next step: A longitudinal study of adolescent English language learners' transitional devices in oral presentations. TESOL Quarterly, 48, 222-251.

Kleinknecht, M. \& Schneider, J. (2013). What do teachers think and feel when analyzing videos of themselves and other teachers teaching? Teaching and Teacher Education, 33, 13-23.

Kobayashi, M. (2003). The role of peer support in ESL students' accomplishment of oral academic tasks. The Canadian Modern Language Review, 59, 337-368.

Kolb, D.A. (1984). Experiential learning: Experience as the source of learning and development. Englewood Cliffs, NJ: Prentice Hall.

Kong, S. C., Shroff, R. H. \& Hung, H. K. (2009). A web enabled video system for self reflection by student teachers using a guiding framework. Australasian Journal of Educational Technology, 25, 544-558.

Lappin-Fortin, K. \& Rye, B. J. (2014). The use of pre-/post-test and self assessment tools in a French pronunciation course. Foreign Language Annals, 47, 300-320.

Mahmud, M. (2013). A study of academic oral presentation anxiety and strategy employment of graduate students. Unpublished master thesis, National Taiwan University of Science and Technology, Taiwan, China.

Marks, M., Fairris, D. \& Beleche, T. (2012). Do course evaluations truly reflect student learning? Economics of Education Review, 31, 709-719.

McFadden, J., Ellis, J., Anwar, T. \& Roehrig, G. (2014). Beginning science teachers' use of a digital video annotation tool to promote reflective practices. Journal of Science Education and Technology, 23, 458-470.

Morita, N. (2000). Discourse socialization through oral classroom activities in a TESL graduate program. TESOL Quarterly, 34, 279-310.

Murphy, K. \& Barry, S. (2016). Feed-forward: Students gaining more from assessment via deeper engagement in video-recorded presentations. Assessment \& Evaluation in Higher Education, 41, 213-227.

Préfontaine, Y. (2013). Perceptions of French fluency in second language speech production. Canadian Modern Language Review, 69, 324-348.

Prusak, K., Dye, B. R., Graham, C. \& Graser, S. (2010). Reliability of pre-service physical education teachers' coding of teaching videos using studiocode analysis software. Journal of Technology and Teacher Education, 18, 131-159. 
Rich, P. \& Hannafin, M. J. (2008). Capturing and assessing evidence of student teacher inquiry. Teaching and Teacher Education, 24, 1426-1440.

Rich, P. J. \& Hannafin, M. J. (2009). Video annotation tools: Technologies to scaffold, structure, and transform teacher reflection. Journal of Teacher Education, 60, 5267.

Robinson, L. \& Kelley, B. (2007). Developing reflective thought in preservice educators: Utilizing role-plays and digital video. Journal of Special Education Technology, 22, 31-43.

Schön, D. A. (1983). The reflective practitioner. London, UK: Temple Smith.

Shepherd, C. \& Hannafin, M. J. (2008). Facilitating professional development through video based, formative assessment e-portfolios. Journal of Computing in Teacher Education, 25, 63-69.

Shepherd, C. \& Hannafin, M. J. (2009). Beyond recollection: Re-examining preservice teacher practices using structured evidence, analysis, and reflection. Journal of Technology and Teacher Education, 17, 229-251.

Shen, C. (2002). Revisiting the relationship between students' achievement and their self-perceptions. Assessment in Education, 9, 161-184.

Smith, E. (2011). Teaching critical reflection. Teaching in Higher Education, 16, 211-223.

Sönmez, D. \& Hakverdi-Can, M. (2012). Videos as an instructional tool in pre-service science teacher education. Eurasian Journal of Educational Research, 46, 141-158.

Sundrarajun, C. \& Kiely, R. (2010). The oral presentation as a context for learning and assessment. Innovation in Language Learning and Teaching, 4, 101-117.

Timperley, H. \& Robinson, V. (2001). Achieving school improvement through challenging and changing teachers' schema. Journal of Educational Change, 2, 281-300.

Tripp, T. \& Rich, P. (2012a). Using video to analyze one's own teaching. British Journal of Educational Technology, 43, 678-704.

Tripp, T. \& Rich, P. (2012b). The influence of video analysis on the process of teacher change. Teaching and Teacher Education, 28, 728-739.

Tsai, S. (2010). Developing and integrating courseware for oral presentations into ESP learning contexts. Computers \& Education, 55, 1245-1258.

Tuan, T. A. \& Neomy, S. (2007). Investigating group planning in preparation for oral presentations in an EFL class in Vietnam. RELC Journal, 38, 104-124. 
Usher, R. (2002). A diversity of doctorates. Higher Education Research and Development, 21, 143-153.

van Es, E. A., Tunney, J., Goldsmith, L. T. \& Seago, N. (2014). A framework for the facilitation of teachers' analysis of video. Journal of Teacher Education, 65, 340356.

van Ginkel, S., Gulikers, J., Biemans, H. \& Mulder, M. (2015). Towards a set of design principles for developing oral presentation competence. Educational Research Review, 14, 62-80.

Watkins, D. A. \& Biggs, J. B. (2001). The paradox of the Chinese learner and beyond. In D. A. Watkins \& J. B. Biggs (Eds.), Teaching the Chinese learner: Psychological and pedagogical perspectives (pp. 3-26). Hong Kong: CERC and HKU.

Welsch, R. G. \& Devlin, P. A. (2004). Developing preservice teachers' reflection: Examining the use of video. Action in Teacher Education, 12, 491-509.

Woodrow, L. (2006). Anxiety and speaking English as a second language. RELC Journal, 37, 308-328.

Yang, L. (2010). Doing a group presentation: Negotiations and challenges experienced by five Chinese ESL students of Commerce at a Canadian university. Language Teaching Research, 14, 141-160.

Zappa-Hollman, S. (2007). Academic presentations across post-secondary contexts. The Canadian Modern Language Review, 63, 455-485.

Zeichner, K. \& Tabachnick, B. R. (1991). Reflections on reflective thinking. In B. R. Tabachnick \& K. Zeichner (Eds.), Issues and practices in inquiry-oriented teacher education (pp. 1-21). Bristol, PA: The Falmer Press. 